\title{
The effect of wild blueberry (Vaccinium angustifolium ) consumption on postprandial serum antioxidant status in human subjects
}

\author{
Colin D. Kay and Bruce J. Holub* \\ Department of Human Biology and Nutritional Sciences, University of Guelph, Ontario, Canada \\ (Received 28 September 2001 - Revised 18 March 2002 - Accepted 18 May 2002)
}

\begin{abstract}
The aim of the present study was to determine whether the consumption of wild blueberries (Vaccinium angustifolium), a concentrated source of non-nutritive antioxidant phytochemicals, would enhance postprandial serum antioxidant status in healthy human subjects. A singleblinded crossover study was performed in a group of eight middle-aged male subjects (3854 years). Subjects consumed a high-fat meal and a control supplement followed 1 week later by the same high-fat meal supplemented with $100.0 \mathrm{~g}$ freeze-dried wild blueberry powder. Upon brachial vein catheterization, fasting and postprandial serum samples were taken sequentially and analysed for lipids and glucose and for serum antioxidant status. Serum antioxidant status was determined using the oxygen radical absorbance capacity (ORAC) assay and the total antioxidant status (TAS) assay. The wild-blueberry treatment was associated with a significant treatment effect as determined by the ORAC assay (water-soluble fraction $\mathrm{ORAC}_{\text {perchloric acid (PCA) }}, P=0 \cdot 04$ ). Significant increases in serum antioxidant status above the controls were observed at $1 \mathrm{~h}\left(\mathrm{ORAC}_{\mathrm{PCA}}(8.5 \%\right.$ greater), $P=0.02$; TAS ( $4.5 \%$ greater), $P=0.05)$, and $4 \mathrm{~h}\left(\mathrm{ORAC}_{\text {total }}(15.0 \%\right.$ greater $), P=0.009$; $\mathrm{ORAC}_{\text {acetone }}$ ( $16.0 \%$ greater), $P=0.007$ ) post-consumption of the high-fat meal. In conclusion, the consumption of wild blueberries, a food source with high in vitro antioxidant properties, is associated with a diet-induced increase in ex vivo serum antioxidant status. It has been suggested that increasing the antioxidant status of serum may result in the reduced risk of many chronic degenerative diseases.
\end{abstract}

Serum antioxidant status: Postprandial oxidation: Anthocyanins: Blueberry: Antioxidant

Epidemiological and interventional studies have suggested that plant-based flavonoids may be protective against many chronic degenerative diseases (Diplock et al. 1998; Liu et al. 2000; Middleton et al. 2000). Anthocyanins are a commonly consumed class of flavonoid (Middleton et al. 2000), having known in vitro antioxidant characteristics (Hertog et al. 1993; Satuè-Gracia et al. 1997). However, their function in vivo has yet to be proven (Rice-Evans, 2001). Lowbush 'wild' blueberries (Vaccinium angustifolium ) are one of the highest fruit sources of anthocyanins (Francis, 1989) and have exhibited one of the highest recorded in vitro antioxidant capacities of various fruits and vegetables tested (Wang et al. 1996; Mazza \& Oomah, 2000). The lowbush 'wild' blueberry as studied herein is of particular interest as it has a higher in vitro antioxidant capacity than the cultivated highbush blueberry (Vaccinium corymbosum; Kalt et al. 1999). Wild blueberries are relatively low in antioxidant vitamins and minerals (Bushway et al. 1983); their in vitro antioxidant capacity has been attributed to their high concentration of phenolic compounds, particularly anthocyanins (Prior et al. 1998; Kalt et al. 1999). The purpose of the present in vivo study was to examine the effect of consuming freeze-dried wild blueberries rich in anthocyanins and phenolic compounds on serum antioxidant status as measured in healthy human subjects. Increasing the serum antioxidant status has been implicated as a possible preventative means to reduce the development of cardiovascular disease (Kaplan \& Aviram, 1999; Salonen et al. 2000), diabetes (Vendemiale et al. 1999) and cancer (Ames et al. 1995; Willett, 2001).

The potential importance of biological markers of oxidative stress in disease has been recognized (Chiesa et al. 1998; Crews et al. 2001). Recently, researchers have determined a correlation between increased ex vivo blood antioxidant status and risk of cardiovascular disease and

\footnotetext{
Abbreviations: ORAC, oxygen radical absorbance capacity; PCA, perchloric acid; TAS, total antioxidant status; Trolox, 6-hydroxy-2,5,7,8tetramethylchroman-2-carboxylic acid.

* Corresponding author: Dr Bruce J. Holub, fax +1 519763 5902, email bhoub@uoguelph.ca
} 
cancer. They found atherosclerotic patients to have significantly lower blood antioxidant status as compared with healthy controls (Durak et al. 2001). Furthermore, a recent Australian study has determined that increasing the serum antioxidant status is associated with a decreased risk of breast cancer (Ching et al. 2002). The oxygen radical absorbance capacity (ORAC) and the total antioxidant status (TAS) assays used in the following trial are recognized as accepted methods of measuring ex vivo antioxidant status (Cao \& Prior, 1998).

\section{Experimental methods}

\section{Subjects}

Eight male subjects (46.9 (SEM 1.9) years, BMI 23.8 (SEM $0.8) \mathrm{kg} / \mathrm{m}^{2}$ ) were recruited from the Guelph (Ont., Canada) area. Baseline characteristics are outlined in Table 1. Participants met all criteria as determined by a medical questionnaire. The principal criteria for eligibility were: (1) absence of clinical disease; (2) no history of renal or gastrointestinal disorders; (3) no alcoholism; (4) no smoking. Subjects taking lipid-altering or blood pressure medications were excluded. Subjects also refrained from taking aspirin or anti-inflammatory medications prior to or during the study, and discontinued all forms of antioxidant supplementation 1 month prior to the investigation. Furthermore, subjects were instructed to maintain a consistent diet throughout the study period. The present study conformed with the ethical guidelines of the University of Guelph (Ont., Canada) and was approved by the Human Subjects Committee. All subjects gave written consent in advance.

\section{Supplementation}

The freeze-dried wild blueberry powder used in this trial was produced at the University of Guelph (Department of Human Biology and Nutritional Sciences) in conjunction with the Ontario Ministry of Agriculture, Food and Rural Affairs (Guelph, Ont., Canada) and the Guelph Food Technology Center (Guelph, Ont., Canada). The powder was produced from wild blueberries of the species Vaccinium angustifolium (lowbush blueberry) obtained from the Sudbury area of Northern Ontario. The chemical composition of the freeze-dried wild blueberry powder and placebo are listed in Table 2 . The blueberry supplement $(100.0 \mathrm{~g})$ contained $1.20 \mathrm{~g}$ total anthocyanins $(42 \%$ total phenolics) and had an ORAC value of $147 \mu \mathrm{mol}$ 6hydroxy-2,5,7,8-tetramethylchroman-2-carboxylic acid (Trolox) equivalents/g (as determined by Brunswick Laboratories, Wareham, MA, USA). The control supplement was matched for digestible carbohydrate and contained $76.4 \mathrm{~g}(1.28 \mathrm{MJ}(305 \mathrm{kcal}))$ glucose (Atlantic Sugar Ltd, Toronto, Ont., Canada), 0.5 g sugar-free Kool Aid (Kraft Canada, Don Mills, Ont., Canada), and had an ORAC value of $5 \mu \mathrm{mol}$ Trolox equivalents/g.

\section{Experimental design}

This study followed a single-blinded crossover design. Subjects were admitted to the Human Testing Lab (Department of Human Biology and Nutritional Sciences, University of Guelph) on the morning of the study in a fasted state $(12-14 \mathrm{~h}$, no alcohol in the previous $24 \mathrm{~h})$. Anthropometric measurements, resting sitting blood pressure and heart rate were obtained before trial commencement. A cannula with an Intima 20 gauge intravenous catheter (Becton Dickinson, Rutherford, NJ, USA) was inserted into the brachial vein and

Table 1. Fasting baseline characteristics of study participants before initiation of treatment* (Mean values with their standard errors for eight subjects)

\begin{tabular}{|c|c|c|c|c|}
\hline \multirow{2}{*}{$\begin{array}{l}\text { Treatment group... } \\
\text { Measurement }\end{array}$} & \multicolumn{2}{|c|}{ Control† } & \multicolumn{2}{|c|}{ Blueberry† } \\
\hline & Mean & SEM & Mean & SEM \\
\hline $\mathrm{ORAC}_{\text {total }}(\mu \mathrm{mol}$ Trolox equivalents/l) & 2407 & 105 & 2436 & 106 \\
\hline ORAC $_{\text {PCA }}(\mu \mathrm{mol}$ Trolox equivalents/l) & 679 & 67 & 656 & 50 \\
\hline $\mathrm{ORAC}_{\text {acetone }}(\mu \mathrm{mol}$ Trolox equivalents/l) & 725 & 123 & 726 & 119 \\
\hline TAS ( $\mu \mathrm{mol}$ Trolox equivalents/l) & 1350 & 20 & 1270 & 20 \\
\hline Serum total cholesterol (mmol/l)‡ & 4.91 & 0.27 & 5.04 & 0.21 \\
\hline Serum triacylglycerol $(\mathrm{mmol} / \mathrm{l}) \S$ & 1.00 & 0.13 & $1 \cdot 20$ & $0 \cdot 18$ \\
\hline Serum HDL-cholesterol (mmol/l) & 1.00 & 0.06 & 1.05 & 0.08 \\
\hline Serum LDL-cholesterol (mmol/l) & 3.45 & 0.30 & 3.44 & 0.21 \\
\hline Serum glucose $\|$ & $5 \cdot 19$ & 0.45 & 5.46 & $0 \cdot 20$ \\
\hline Systolic blood pressure (mmHg) & 118 & 7 & 115 & 5 \\
\hline Diastolic blood pressure $(\mathrm{mmHg})$ & 76 & 5 & 72 & 4 \\
\hline Heart rate (beats/min) & 66 & 3 & 70 & 4 \\
\hline
\end{tabular}

ORAC, oxygen radical absorbance capacity; Trolox, 6-hydroxy-2,5,7,8-tetramethylchroman-2-carboxylic acid; PCA, perchloric acid; TAS, total antioxidant status.

* Serum lipids and glucose analyses were conducted at an Ontario Ministry of Health Licensing and Inspection Branch licensed laboratory (Guelph General Hospital Core Laboratory, MDS Laboratory Services, Guelph, Ont., Canada). Serum ORAC was determined by Genox Laboratories, Baltimore MD, USA.

†There were no significant differences for baseline $(t 0)$ measures between treatment groups (paired $t$ test): $P>0.05$.

† For serum cholesterol $1 \mathrm{mmol} / \mathrm{l}=38.57 \mathrm{mg} / \mathrm{dl}$.

$\S$ For serum triacylglycerol $1 \mathrm{mmol} / \mathrm{I}=88.57 \mathrm{mg} / \mathrm{dl}$.

|| For serum glucose $1 \mathrm{mmol}=17.9 \mathrm{mg} / \mathrm{dl}$. 
Table 2. Composition of treatment supplements

\begin{tabular}{lcc}
\hline Component & Freeze-dried blueberry supplement & Control supplement十 \\
\hline ORAC $(\mu \mathrm{mol}$ Trolox equivalents $/ \mathrm{g}) \ddagger$ & 147 & 5 \\
Total phenolics $(\mathrm{g} / \mathrm{kg}) \S$ & 27.9 & 0.0 \\
Anthocyanins $(\mathrm{g} / \mathrm{kg}) \S$ & 11.6 & 0.0 \\
Vitamin C $(\mathrm{g} / \mathrm{kg})$ & $0 \cdot 1$ & 0.0 \\
Digestible carbohydrate $(\mathrm{g} / \mathrm{kg}) \|$ & 764 & 764 \\
Total dietary fibre $(\mathrm{g} / \mathrm{kg}) \|$ & 178 & 0.0 \\
Protein $(\mathrm{g} / \mathrm{kg}) \|$ & 27 & 0.0 \\
Fat $(\mathrm{g} / \mathrm{kg}) \|$ & 24 & 0.0 \\
Ash $($ mineral content) $(\mathrm{g} / \mathrm{kg}) \|$ & 10 & 0.0 \\
Energy $\|$ & & \\
$\mathrm{kcal} / \mathrm{g}$ & 3.38 & 3.05 \\
$\mathrm{~kJ} / \mathrm{g}$ & 14.10 & 12.72 \\
\hline
\end{tabular}

ORAC, oxygen radical absorbance capacity; Trolox, 6-hydroxy-2,5,7,8-tetramethylchroman-2-carboxylic acid.

*Lowbush 'wild' blueberry (Vaccinium angustifolium); for details of preparation, see p. 390.

† The control supplement contained $76.4 \mathrm{~g}$ glucose (Atlantic Sugar Ltd, Toronto, Ont., Canada), $0.5 \mathrm{~g}$ sugar-free Kool aid (Kraft Canada, Don Mills, Ont., Canada; For details, see p. 390.

$\ddagger$ Analysis conducted by Brunswick Laboratories, Wareham, MA, USA.

$\S H P L C$ analysis of phytochemicals (total phenolics and anthocyanins within the freeze-dried blueberry supplement conducted by Brunswick Laboratories, Wareham, MA, USA.

\|Chemical analyses of freeze-dried blueberry powder conducted by Maxxam Analytics Inc., Mississauga, Ont., Canada.

a fasting blood sample was drawn. Subjects received the control supplement (dissolved in $500 \mathrm{ml}$ water) with a high-fat meal $(3.56 \mathrm{MJ}$ ( $853 \mathrm{kcal}), 46.7 \mathrm{~g}$ fat of which $15.5 \mathrm{~g}$ was saturated fat, as determined by Maxxam Analytics Inc., Mississauga, Ont., Canada) consisting of one Egg McMuffin, one Sausage McMuffin and two hash brown patties (McDonald's Corporation). The macronutrient and vitamin composition of the high-fat meal is shown in Table 3. Initiation of the high-fat meal was taken as $t 0$; subsequent blood samples were taken at 1, 2, 3 and $4 \mathrm{~h}$. Procedures were repeated (on the same subjects) $7 \mathrm{~d}$ later using the same high-fat meal, with $100 \cdot 0 \mathrm{~g}$ freeze-dried wild blueberry powder (dispersed in $500 \mathrm{ml}$ water) in place of the control supplement.

\section{Sampling procedures}

Blood was drawn from a brachial vein catheter into evacuated glass tubes (Vacutainer; Becton Dickinson). Samples were allowed to clot at room temperature for $25 \mathrm{~min}$. Samples were then immediately centrifuged $(3000 \mathrm{rpm}$,

Table 3. Composition of high-fat meal ${ }^{*}$

\begin{tabular}{|c|c|c|}
\hline Component & Amount & \% Energy \\
\hline Digestible carbohydrate $(\mathrm{g}) \dagger$ & $75 \cdot 2$ & $35 \cdot 4$ \\
\hline Protein $(g) \dagger$ & $32 \cdot 4$ & $15 \cdot 3$ \\
\hline Fat $(g) \dagger$ & $46 \cdot 7$ & $49 \cdot 3$ \\
\hline Total dietary fibre $(\mathrm{g}) \dagger$ & 4.5 & \\
\hline Ash (mineral content) $(\mathrm{g}) \dagger$ & $9 \cdot 1$ & \\
\hline Vitamin C (mg) & $6 \cdot 0$ & \\
\hline Vitamin E (mg) & $2 \cdot 1$ & \\
\hline \multicolumn{3}{|l|}{ Energy† } \\
\hline kcal† & 853 & \\
\hline KJ† & 356 & \\
\hline
\end{tabular}

*The meal consisted of one Egg McMuffin, one sausage McMuffin and two hash brown patties (McDonald's Corporation).

†Chemical analyses of the high-fat meal conducted by Maxxam Analytics Inc., Mississauga, Ont., Canada.
$1000 \mathrm{~g}$ ) for $15 \mathrm{~min}$ at $5-15^{\circ} \mathrm{C}$ to recover serum. Serum was extracted and divided into portions in $2 \mathrm{ml}$ vials (Cryovial; Fisher Scientific Ltd, Nepean, Ont., Canada) over an iced-water bath $\left(3-4^{\circ} \mathrm{C}\right)$ using disposable glass pipettes. The serum was then snap-frozen in liquid $\mathrm{N}_{2}$ and stored at $-80^{\circ} \mathrm{C}$. All glass was pre-washed in a $0.2 \mathrm{M}-\mathrm{HCl}$ solution and rinsed three times with distilled, de-ionized $\mathrm{H}_{2} \mathrm{O}$ to remove possible contaminants (metal ions).

\section{Serum antioxidant capacity}

Serum antioxidant capacity was measured using the ORAC (ORAC $_{\text {total }}$, ORAC $_{\text {perchloric acid (PCA) }}$ and ORAC acetone fractions) and TAS assays. Serum ORAC was determined by Genox Laboratories, Baltimore, MD, USA, using the ORAC assay as outlined by Cao et al. (1993). Modifications to the ORAC assay allow for the isolation of lipid- and watersoluble phases of the serum sample. The $\mathrm{ORAC}_{\mathrm{PCA}}$ fraction (serum treated with PCA) is a non-protein fraction that preserves the water-soluble antioxidants within the sample. $\mathrm{ORAC}_{\text {acetone }}$ (serum treated with acetone) is a non-protein fraction containing both water-soluble and lipid-soluble antioxidants (Cao \& Prior, 1998). Briefly, the ORAC assay was conducted using the automated COBAS FARA II spectrofluorometric analyser (Roche Diagnostics, Basel, Switzerland) with fluorescent filters at an excitation wavelength of $546 \mathrm{~nm}$ and an emission wavelength of $565 \mathrm{~nm}$. $\beta$-Phycoerythrin was used as the target molecule for free-radical attack, with 2,2-azobis(2-amidinopropane) dihydrochloride as the peroxyl radical generator. Trolox, an aqueous soluble vitamin $\mathrm{E}$ analogue, was used as a control standard. Fluorescence of $\beta$-phycoerythrin was recorded every $55 \mathrm{~s}$ and expressed relative to the initial reading. Final results were calculated by using the differences of the areas under the $\beta$-phycoerythrin decay curves between the blank and the sample. ORAC readings are expressed as $\mu$ mol Trolox equivalents, where 1 Trolox equivalent equals the net protection area under the curve 
provided by $1 \mu$ mol Trolox. TAS was measured on an automated Hitachi 911 Biochemical Analyzer using the Randox-TEAC assay (Randox Laboratories, Mississauga, Ont., Canada). Briefly, the assay is based on the inhibition by antioxidants to absorb free radicals. Plasma samples were added to a 2.21-azinobis-(3-ethylbenzthiazoline-6sulfonate) radical solution. The change in radical concentration over a $10 \mathrm{~min}$ incubation period was monitored spectrophotometrically $(600 \mathrm{~nm})$ and compared with the decrease of a known standard (Trolox). Specifics of the ORAC and comparisons between the ORAC and TAS assays have been outlined by Cao \& Prior (1998).

\section{Blood lipids}

Serum lipid and glucose analyses were conducted at an Ontario Ministry of Health Licensing and Inspection Branch licensed laboratory (Guelph General Hospital Core Laboratory, MDS Laboratory Services, Guelph, Ont., Canada). Total cholesterol, HDL-cholesterol, triacylglycerol and glucose were analysed on a Synchron CX DELTA automated sample processor (Beckman Coulter Inc., Fullerton, CA, USA) with the appropriate reagent systems. LDL-cholesterol was calculated using the Friedewald equation (Friedewald et al. 1972).

\section{Vitamin and phytochemical analysis}

Total vitamin E concentration was analysed after saponification followed by isooctane extraction and separation by normal-phase chromatography (Liu et al. 1996). Vitamin $\mathrm{C}$ was determined by HPLC following deproteinization (Speek et al. 1984). Both vitamin C and E were quantified by fluorescent detection. Total anthocyanin and total phenolic concentrations (within the treatment supplements) were determined by Brunswick Laboratories (Wareham, MA, USA) using automated HPLC technologies (ESA 582 HPLC (binary pump) with u.v.-visable twelve channel CoulArray detectors) and quantified via u.v. visualization. Total anthocyanin concentration was determined using cyanidin-3-glucoside as a standard.

\section{Statistical analysis}

Results are expressed as mean values with their standard errors. Baseline characteristics of the treatment groups were compared using independent paired $t$ tests. The effects of diet treatment (freeze-dried wild blueberry powder) and postprandial times, as well as interactions between them, were determined by repeated measures ANOVA using the Statistical Analysis Systems statistical software package (version 6.1; SAS Institute Inc., Cary, NC, USA). Linear regression analysis was also conducted using SAS. Post-hoc tests using the least squared difference test and unpaired $t$ tests were conducted to determine differences between individual group means.

\section{Results \\ Blood lipids and glucose}

The baseline characteristics of the eight subjects are given in Table 1. No significant differences in the fasting serum values were observed between the two treatment groups $(P>0.05)$. Results of supplementation on postprandial serum lipid and glucose concentrations are shown in Table 4. There were no significant time or treatment effects with respect to postprandial serum cholesterol concentrations.

The consumption of the treatment meals was associated with a significant time effect $(P=0.001)$ for the appearance of triacylglyerol (125\% greater then baseline). The rise in triacylglycerol following consumption of a high-fat meal is consistent with results in the literature (Ryu et al. 1992). There were no significant differences between the two groups for the postprandial appearance of serum triacylglyerol $(P>0.05)$ at any time point. The increase in serum triacylglyerol over time was positively correlated with an increase in $\mathrm{ORAC}_{\text {total }}(P=0.0001)$.

The blueberry treatment was associated with a significant time $(P=0.002)$ and treatment $(P=0.002)$ effect for the appearance of serum glucose, however, there was no treatment $\times$ time interaction and the time and treatment effects did not correlate with changes in ORAC or TAS $(P>0 \cdot 05)$. Serum glucose concentrations were significantly higher in the blueberry-treatment group at $3(P=0.03)$ and $4 \mathrm{~h}(P=0 \cdot 03)$.

\section{Serum antioxidant status}

The blueberry treatment was associated with a significant treatment effect as represented by an increase in serum antioxidant status above the control group for the ORAC assay, PCA fraction (ORAC PCA $P=0.04$ ) (Fig 1(a)). Furthermore, the consumption of both of the treatment meals was associated with a significant time effect, which was a result of a progressive increase in serum ORAC $\mathrm{O}_{\text {total }}$ $(P<0.001)$ and ORAC $_{\text {acetone }}(P<0.001)$ (Fig. 2 (a and b)) over time.

The $\mathrm{ORAC}_{\mathrm{PCA}}$ fraction revealed a peak maximal watersoluble response occurring at $1 \mathrm{~h}(P=0.02)$ yielding an $8.5 \%$ increase in serum antioxidant status over the control (Fig. 1(a)). This was supported by a significant increase $(4.5 \%)$ in TAS at $1 \mathrm{~h}(P=0.05)$ (Fig. 1(b)). The protective effects witnessed at $1 \mathrm{~h}$ in both ORAC $\mathrm{OCA}_{\mathrm{PCA}}$ and TAS returned to baseline values $(P>0.05)$ for the $2-4 \mathrm{~h}$ sample points (Fig. 1 (a,b)). In contrast, the blueberry treatment was associated with a significant increase in serum total and lipid-soluble antioxidant status $(15.0 \%$ increase in $\mathrm{ORAC}_{\text {total }}, P=0.009 ; 16.0 \%$ increase in ORAC $\mathrm{Ocetone}_{\text {, }}$ $P=0.007$ ) above the control at $4 \mathrm{~h}$ (Fig. 2 (a and b)).

\section{Discussion}

Diet and oxidative stress have been implicated in the development of cardiovascular disease (Castelli, 1998; Kaplan \& Aviram, 1999), diabetes (Georgopoulos, 1999; Vendemiale et al. 1999) and cancer (Ames et al. 1995; Willett, 2001). Increasing the serum antioxidant status 
Table 4. Effects of nutritional supplementation on serum lipid and glucose concentrations§ (Mean values with their standards errors for eight subjects)

\begin{tabular}{|c|c|c|c|c|c|c|c|}
\hline & \multirow[b]{3}{*}{ Time (h) } & \multicolumn{4}{|c|}{ Treatment group $\ddagger$} & \multirow{2}{*}{\multicolumn{2}{|c|}{$\begin{array}{l}\text { Statistical significance } \\
\text { of effect (ANOVA): } P\end{array}$}} \\
\hline & & \multicolumn{2}{|c|}{ Control } & \multicolumn{2}{|c|}{ Blueberry } & & \\
\hline & & Mean & SEM & Mean & SEM & Time & Treatment \\
\hline \multirow[t]{5}{*}{ Triacylglycerol $(\mathrm{mmol} / \mathrm{l}) \|$} & 0 & 1.00 & 0.13 & 1.20 & 0.18 & $<0.0001$ & \\
\hline & 1 & $1 \cdot 22^{*}$ & 0.15 & $1 \cdot 27^{*}$ & 0.21 & & \\
\hline & 2 & $1.50^{*}$ & 0.20 & $1.57^{*}$ & 0.27 & & \\
\hline & 3 & $1.87^{*}$ & 0.29 & $2 \cdot 10^{*}$ & 0.38 & & \\
\hline & 4 & $2 \cdot 12^{\star}$ & 0.36 & $2 \cdot 62^{\star}$ & 0.47 & & \\
\hline \multirow[t]{5}{*}{ Glucose $(\mathrm{mmol} / \mathrm{l}) \|$} & 0 & $5 \cdot 19$ & 0.20 & 5.46 & $0 \cdot 15$ & $<0.005$ & $<0.005$ \\
\hline & 1 & 5.36 & 0.66 & $6 \cdot 40$ & 0.55 & & \\
\hline & 2 & $4.41^{*}$ & 0.22 & 5.01 & 0.27 & & \\
\hline & 3 & $4.01^{*}$ & 0.22 & $4 \cdot 79^{*} \dagger$ & 0.22 & & \\
\hline & 4 & $4.42^{*}$ & 0.23 & $5 \cdot 00^{*} \dagger$ & 0.11 & & \\
\hline \multirow[t]{5}{*}{ Total cholesterol $(\mathrm{mmol} / \mathrm{l}) \|$} & 0 & 4.91 & 0.27 & 5.04 & 0.21 & & \\
\hline & 1 & 4.96 & 0.31 & 5.03 & 0.26 & & \\
\hline & 2 & 4.98 & 0.32 & 5.07 & 0.23 & & \\
\hline & 3 & 4.86 & 0.30 & 5.03 & 0.28 & & \\
\hline & 4 & 4.84 & 0.32 & 5.03 & 0.29 & & \\
\hline \multirow[t]{5}{*}{ LDL-cholesterol $(\mathrm{mmol} / \mathrm{l}) \|$} & 0 & 3.44 & 0.30 & 3.44 & 0.21 & & \\
\hline & 1 & 3.37 & 0.32 & 3.41 & 0.25 & & \\
\hline & 2 & $3 \cdot 29^{*}$ & 0.30 & $3 \cdot 32^{*}$ & 0.21 & & \\
\hline & 3 & $3.03^{*}$ & 0.27 & $3.07^{*}$ & 0.23 & & \\
\hline & 4 & $2 \cdot 91^{*}$ & 0.31 & $2 \cdot 86^{*}$ & 0.24 & & \\
\hline \multirow[t]{5}{*}{ HDL-cholesterol (mmol/l)|| } & 0 & 1.00 & 0.06 & 1.05 & 0.08 & & \\
\hline & 1 & 1.03 & 0.08 & 1.04 & 0.09 & & \\
\hline & 2 & 1.00 & 0.06 & 1.02 & 0.09 & & \\
\hline & 3 & 0.97 & 0.07 & 0.99 & 0.08 & & \\
\hline & 4 & 0.95 & 0.08 & 0.96 & 0.08 & & \\
\hline
\end{tabular}

Mean values were significantly different from those at $t 0$ (paired $t$ test): ${ }^{*} P<0.05$.

Mean values were significantly different from those of the control group (least squares difference test): $\dagger P<0.05$.

¥There were no significant differences for baseline measures $(t 0)$ between treatment groups (paired $t$ test): $P>0.05$

$\S$ For details of subjects, test meals and supplements, see Tables 1-3 pp. 390-391.

\| Serum lipids and glucose analyses were conducted at an Ontario Ministry of Health Licensing and Inspection Branch

licensed laboratory (Guelph General Hospital Core Laboratory Services, Guelph, Ont., Canada).

I LDL-cholesterol was calculated using the Friedwald equation (Friedwald et al. 1972).

has been proposed as a preventative means to reduce the development of these diseases (Kaplan \& Aviram, 1999; Vendemiale et al. 1999; Willett, 2001). The aim of the present trial was to examine the effects of wild-blueberry supplementation on serum antioxidant status in healthy human volunteers. Previous studies have demonstrated the in vitro antioxidant properties of wild blueberries to be higher than that of most fruits and vegetables, as well as that of cultivated highbush blueberries (Satué-Gracia et al. 1997; Prior et al. 1998). The present study indicates the antioxidant potential for the blueberry or a blueberry extract as a functional food under physiological conditions.

\section{Supplementation}

The decision to feed the subjects a high-fat meal was based on the evidence that the consumption of a high-fat meal is associated with postprandial lipaemia and increased oxidative stress (Papas, 1996; Hennig et al. 2001). We therefore aimed to create a dietary stress similar to that encountered when eating a typical 'fast-food' meal. The decision to supplement the subjects with $100 \cdot 0 \mathrm{~g}$ dried blueberry powder was based on achieving a maximal level of anthocyanins without exceeding a dietary acceptable level of fibre (Howarth et al. 2001). The $100 \cdot 0 \mathrm{~g}$ blueberry powder supplement contained $17.8 \mathrm{~g}$ fibre. It is important to note that $100.0 \mathrm{~g}$ dried blueberry powder is the equivalent of approximately 500-650 g whole blueberries, which exceeds that of a typical serving size. The design of the present study does not allow for the determination of the minimal dose required to achieve a significant response; however, now that an effect has been observed, subsequent studies are needed to determine if a statistically significant response could be observed with lower doses of blueberries. Furthermore, if supplementation is considered beneficial, further refinements could decrease the quantity of powder needed considerably, as well as producing a blueberry extract with high concentrations of berry phytochemicals.

\section{Possible effect of other dietary components on serum antioxidant status}

The blueberry-supplemented group as studied herein was provided with $17.8 \mathrm{~g}$ fibre more than the control group, but this did not result in the attenuation of postprandial serum glucose or triacylglyerol absorption (Table 4). Previous studies have shown that certain fibres can attenuate postprandial increases in serum glucose (Ou et al. 2001). 


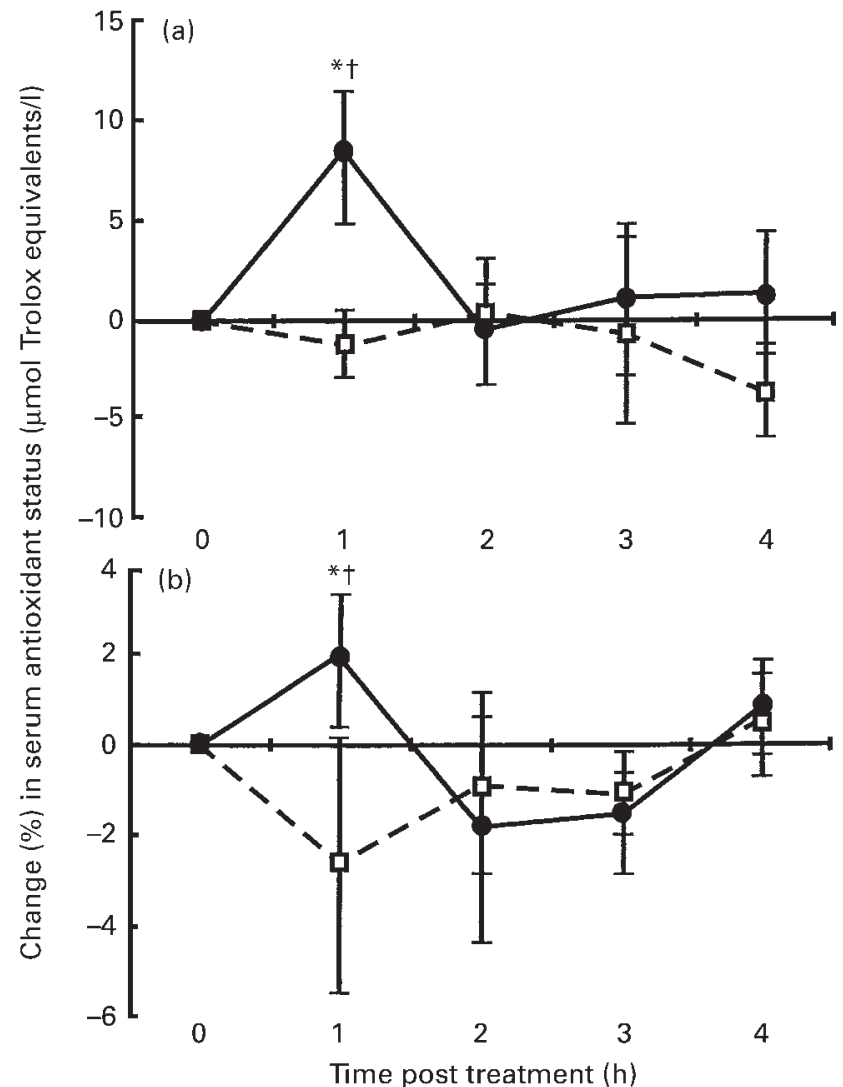

Fig. 1. Change (\%) in serum antioxidant status over $4 \mathrm{~h}$ following the consumption of a high-fat meal with a control supplement $(\square)$ or $100.0 \mathrm{~g}$ freeze-dried wild blueberry powder (Vaccinium angustifolium) (๑). Serum antioxidant status measured as: (a) oxygen radical absorbance capacity (ORAC) perchloric acid (PCA) (water-soluble fraction) (Genox Laboratories, Baltimore, MD, USA); (b) total antioxidant status (TAS) (Randox-TEAC assay; Randox Laboratories, Mississauga, Ont., Canada). Trolox, 6-hydroxy-2,5,7,8-tetramethylchroman-2-carboxylic acid. For details of test meal, supplements and procedures, see Tables 2 and 3 and pp. 390 and 391. Values are means for eight subjects with standard errors shown by vertical bars. Mean values were significantly different from those of the control group at a given time point (least squared difference test): ${ }^{*} P<0.05$. Mean values were significantly different from those at baseline $(t 0)$ (paired $t$ test): $† P<0.05$.

The blueberry treatment was associated with a significant time and treatment effect for the appearance of serum glucose. This glucose effect was significantly $(P<0.05)$ different from the control group at the 3 and $4 \mathrm{~h}$ sample points. We attribute the glucose effect to differences in monosaccharide content between the control and the blueberry treatment. Blueberries contain a high concentration of fructose (up to 50.0\% digestible carbohydrate; Payne, 2000); however, the control supplement contained only glucose (dextrose). Previous research has determined that fructose accompanied by a similar or equivalent concentration of glucose may enhance glucose and fructose absorption (Perman, 1996) and delay glucose utilization (Shi et al. 1997). The conversion of fructose to glucose by the liver and subsequent release of serum glucose into the systemic circulation results in a further delayed appearance of glucose following a postprandial fructose load (Chandramouli et al. 1993). Furthermore, glucose is an

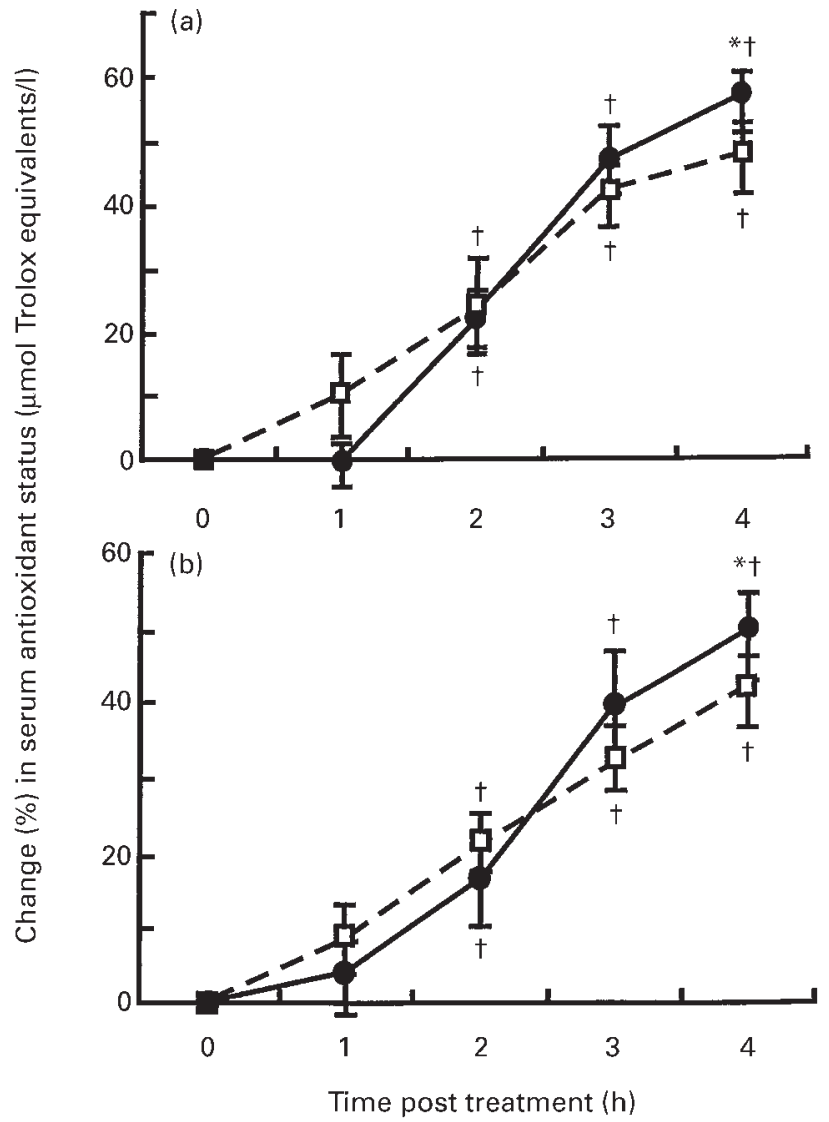

Fig. 2. Change (\%) in serum antioxidant status over $4 \mathrm{~h}$ following the consumption of a high-fat meal with a control supplement $(\square)$ or $100.0 \mathrm{~g}$ freeze-dried wild blueberry powder (Vaccinium angustifolium) (@). Serum antioxidant status measured as: (a) oxygen radical absorbance capacity (ORAC) total (total fraction) (Genox

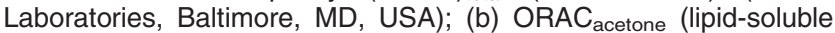
and water-soluble fraction) (Genox Laboratories). Trolox, 6hydroxy-2,5,7,8-tetramethylchroman-2-carboxylic acid. For details of test meal, supplements and procedures, see Tables 2 and 3 and pp. 390 and 391. Values are means for eight subjects with standard errors shown by vertical bars. Mean values were significantly different from those of the control group at a given time point (least squared difference test): ${ }^{\star} P<0.05$. Mean values were significantly different from those at baseline ( $t 0)$ (paired $t$ test): $† P<0.05$.

unlikely contributor to the ORAC values observed with the blueberry treatment. In fact the ORAC value for the treatment supplement containing mainly glucose was negligible (5 ORAC units). In addition, there was no correlation between postprandial glucose concentration and ORAC or TAS results $(P>0 \cdot 05)$. We attribute the glucose effect experienced in the blueberry-treatment group to differences in fructose concentration between the blueberry treatment and the control treatment and not the difference in fibre concentrations between the two groups. In addition, the blueberry treatment was not associated with an attenuation of postprandial triacylglyerol absorption as is sometimes observed with fibre consumption (Scheppach et al. 2001). Furthermore, previous researchers have determined that the high in vitro antioxidant properties of the blueberry are not a result of their fibre content (Bushway et al. 1983; Prior et al. 1998). We therefore conclude that the difference in fibre content between the treatment groups was not 
substantial enough to have been responsible for the observed effects on serum glucose, lipids or antioxidant status.

An increase in ORAC $_{\text {total }}$ and $\mathrm{ORAC}_{\text {acetone }}$ following consumption of the high-fat meal occurred in the control group (as well as the blueberry-treatment group) regardless of an essentially antioxidant-free control supplement. No such increase was found in the control group when using the TAS assay. This dissimilarity in findings between the two assays is likely to be a result of mechanistic differences between the assays. The TAS assay measures the inhibition of free radical action, which is similar to the basis of the ORAC assay; however, the TAS assay measures the inhibition at a fixed time $(10 \mathrm{~min})$ whereas the ORAC assay measures the time it takes for this reaction to reach completion ( $\geq 60 \mathrm{~min}$ ). Measuring the reaction to completion allows for the contribution of all oxidizable substrates within the sample to prevent oxidation of the target molecule. Since the TAS assay has a fixed inhibition time, it has a greater ability to reflect the effect of fasteracting antioxidants in the serum (i.e. water-soluble antioxidants) and not the slower-oxidizable substrates. This is probably why there was no increase in serum antioxidant status following ingestion of the high-fat meal in the control group when using the TAS assay (Fig. 1(B)). This unexpected increase in antioxidant potential in the control group may therefore reflect the stress imposed by the highfat meal as exhibited with the ORAC assay. We rationalize this latter effect with the following possible explanations. First, the ORAC assay (Cao et al. 1993) measures the area under the curve of the decay of a target molecule ( $\beta$-phycoerythrin). Any potentially oxidizable substrates (i.e. amino acids, fatty acids or carbohydrates) present in the sample can theoretically retard the decay of the target (Cao \& Prior, 2000). We consider that the fatty acids may have been the primary substrates causing this antioxidant effect in the control group (as well as in the blueberry-treatment group). Since the results obtained from the $\mathrm{ORAC}_{\text {total }}$ (containing proteins) and $\mathrm{ORAC}_{\text {acetone }}$ (void of proteins) assays varied by only a small margin, it is safe to assume that proteins within the serum samples were probably not acting as the primary substrates for oxidation. Second, glucose has very little antioxidant activity when analysed using ORAC, thus eliminating carbohydrate as a main substrate contributing to the antioxidant effect of the treatments. Third, the high-fat meal contained only $6.0 \mathrm{mg}$ vitamin $\mathrm{C}$ and $2.1 \mathrm{mg}$ vitamin E. Previous studies using much higher concentrations (20-90-fold) have shown no effect on serum oxidation (Priemé et al. 1997; van den Berg et al. 2001). Other possible explanations such as the up-regulation of endogenous antioxidant enzymes during the postprandial state will not be explored in the present discussion, as there are insufficient results in the literature at the present time to support this concept. Finally, the postprandial appearance of serum triacyglycerol correlated significantly $(P<0.001)$ with the $\mathrm{ORAC}_{\text {total }}$ and $\mathrm{ORAC}_{\text {acetone }}$ results. Therefore, it is logical to assume that the increase in $\mathrm{ORAC}_{\text {total }}$ and $\mathrm{ORAC}_{\text {acetone, }}$ as exhibited in the control group, is likely to be a result of the inability of the ORAC assay to differentiate between fatty acid oxidation (non-enzymatic) and the free radicalquenching capacity of serum antioxidants.

\section{Experimental design}

The design of the present study does not allow us to determine what compounds within the blueberry are responsible for the increase in serum antioxidant status observed in this trial. However, it is most likely that anthocyanins within the blueberry are the major contributing phenolic compounds responsible for this effect. Anthocyanins comprise the highest concentration of all phenolic subgroups in the blueberry (Wang \& Lin, 2000). Previous research has determined that the ORAC value of the blueberry correlates more strongly with anthocyanins than with total phenolics in the berry (Mazza \& Oomah, 2000). Furthermore, the antioxidant properties of anthocyanins have been validated using other systems of oxidation such as their ability to prevent LDL oxidation in vitro (Laplaud et al. 1997). Therefore, although we have not proven directly that anthocyanins are responsible for the observed antioxidant effect in the blueberry-treatment group, studies have shown that the in vitro antioxidant properties of wild blueberries are mainly a result of their high concentration of anthocyanins (along with other phenolics) and not their concentrations of antioxidant vitamins, minerals or fibre (Bushway et al. 1983; Prior et al. 1998; Kalt et al. 1999).

Subsequent studies from our group (J Mazza, CD Kay and BJ Holub, unpublished results) have concluded that supplementation with $100 \cdot 0 \mathrm{~g}$ freeze-dried wild blueberry powder results in the absorption and appearance of intact anthocyanins in the postprandial serum samples. We cannot unequivocally exclude the possibility of other absorbed phenolics contributing to the antioxidant effect as observed herein. We can, however, confidently attribute the observed effects to the consumption of the wild blueberry powder.

Although we have demonstrated that supplementation with a freeze-dried wild blueberry powder increased serum antioxidant status, the magnitude of the observed response cannot be arbitrarily translated into a decreased risk of chronic degenerative disease. Studies have indicated an increased risk of chronic disorders in individuals with low levels of fasting antioxidants (Lachance, 1998). However, at the present time there are insufficient results in the literature to determine the magnitude of chronic degenerative disease risk reduction with given increases in serum antioxidant status. There is current evidence from human subjects indicating that increased total serum antioxidant status (as determined by the TAS assay) is associated with significant reductions in breast cancer risk (Ching et al. 2002).

\section{The effect of the blueberry treatment on serum antioxidant status}

The blueberry treatment was associated with a significantly $(P<0.05)$ higher increase in serum antioxidant status relative to the control at 1 and $4 \mathrm{~h}$ post consumption on the high-fat meal. Peak serum concentration of anthocyanins as determined previously (Cao et al. 2001) occurred at 60-70 min after consumption. This is consistent with our present findings of a maximum water-soluble antioxidant 
effect at $1 \mathrm{~h}$. In our present study, $\mathrm{ORAC}_{\mathrm{PCA}}$ peaked at $1 \mathrm{~h}$ in the blueberry-treatment group, when it was significantly $(P<0.05)$ different from that of the control group, and returned to baseline by the $2 \mathrm{~h}$ sample point. This difference at $1 \mathrm{~h}$ paralleled that of the TAS results. In contrast, the changes in ORAC $\mathrm{Ctal}_{\text {tol }}$ and $\mathrm{ORAC}_{\text {acetone }}$ did not become significant $(P<0.05)$ until the $4 \mathrm{~h}$ sample point. We rationalize this to be a result of the water-soluble anthocyanins and other phenolics within the blueberries, which may possibly be competing with less reactive antioxidants and endogenous enzymes, therefore sparing them for later postprandial oxidation reactions. It is also possible that the anthocyanins together with other phenolic compounds within the blueberry may be regenerating oxidized lipid-soluble antioxidants in the serum, similar to the process of vitamin $\mathrm{E}$ regeneration by vitamin $\mathrm{C}$ (Niki, 1996). Although the blueberry treatment contained $10.6 \mathrm{mg}$ vitamin $\mathrm{C}$ more than the control, we do not believe this level could be responsible for any of the observed changes in serum antioxidant status. Previous research using much higher concentrations (10-45-fold) have shown no effect on serum antioxidant status (Priemé et al. 1997; van den Berg et al. 2001). Furthermore, it has been reported that ascorbate makes very little contribution $(0 \cdot 8-$ $1.5 \%)$ to the total in vitro antioxidant capacity of the blueberry (Prior et al. 1998; Kalt et al. 1999).

Decreased serum antioxidant status has been suggested as a risk factor in cardiovascular disease (Kaplan \& Aviram, 1999), diabetes (Georgopoulos, 1999; Vendemiale et al. 1999), and cancer (Ames et al. 1995; Willett, 2001). The reduced risk of these diseases associated with increased consumption of fruits and vegetables may be attributed to the non-nutritive antioxidant phytochemicals within such foods (Loft \& Poulsen, 1996; Scalber \& Williamson, 2000) and not to their levels of traditional antioxidant vitamins and minerals (Steinmetz \& Potter, 1996; Priemé et al. 1997). It is likely, however, that any such protective effects on chronic disorders occur as a result of interactions between traditional antioxidants, endogenous enzymes, and antioxidant phytochemicals.

\section{Conclusions}

In conclusion, we have demonstrated that supplementation with a freeze-dried wild blueberry powder increased serum antioxidant status following the consumption of a high-fat meal. Increasing the serum antioxidant status has been suggested as a possible method of reducing the risk of many chronic degenerative disorders (Kaplan \& Aviram, 1999; Georgopoulos, 1999; Vendemiale et al. 1999; Willett, 2001). In vitro analysis of the blueberry shows it to have highly active antioxidant characteristics. The present study provides physiological evidence for the enhancement of postprandial serum antioxidant status in human volunteers consuming a blueberry-supplemented meal.

\section{Acknowledgements}

The study was supported by the Ontario Ministry of Agriculture, Food and Rural Affairs, Guelph, Ont., Canada.

\section{References}

Ames BN, Gold LS \& Willett WC (1995) The causes and prevention of cancer. Proceedings of the National Academy of Sciences USA 92, 5258-5265.

Bushway RB, McGann DF, Cook WP \& Bushway AA (1983) Mineral and vitamin content of lowbush blueberries (Vaccinium angustifolium). Journal of Food Science 48, 18781880.

Cao G, Alessio HM \& Cutler RG (1993) Oxygen-radical absorbance capacity assay for antioxidants. Free Radical Biology and Medicine 14, 303-311.

Cao G, Muccitelli HU, Sánchez-Moreno C \& Prior RL (2001) Anthocyanins are absorbed in glycated forms in elderly women: a pharmacokinetic study. American Journal of Clinical Nutrition 73, 920-926.

Cao G \& Prior RL (1998) Comparison of different analytical methods for assessing total antioxidant capacity of human serum. American Journal of Clinical Nutrition 44, 1309-1315.

Cao G \& Prior RL (2000) Postprandial increases in serum antioxidant capacity in older women. Journal of Applied Physiology 89, 877-883.

Castelli WP (1998) The new pathophysiology of coronary artery disease. American Journal of Cardiology 82, 60T-65T.

Chandramouli V, Kumaran K, Ekberg K, Wahren J \& Landau BR (1993) Quantitation of the pathways followed in the conversion of fructose to glucose in liver. Metabolism 42, 1420-1423.

Chieas R, Melissano G, Castellano R, Astore D, Marone EM, Grossi A, Maggi E, Finardi G, Casac A, Bellonmo G \& Pavia M (1998) In search of biological markers of high-risk carotid artery atherosclerotic plaque: enhanced LDL oxidation. Annals of Vascular Surgery 12, 1-9.

Ching S, Ingram D, Hahnel R, Beilby J \& Rossi E (2002) Serum levels of micronutrients, antioxidants and total antioxidant status predict risk of breast cancer in a case control study. Journal of Nutrition 132, 303-306.

Crews W, Alink G, Anderson R, Braesco V, Holst B, Maiani G, Ovesen L, Scotter M, Solfizzo M, van den Berg H, Verhagen H \& Williamson G (2001) A critical assessment of some biomarker approaches linked with dietary intake. British Journal of Nutrition 86, S5-S35.

Diplock AT, Charleux JL, Grozier-Willi G, Kok FJ, Rice-Evans C, Roberfroid M, Stahl W \& Vina-Ribes J (1998) Functional food science and defence against reactive oxidative species. British Journal of Nutrition 80, S77-S112.

Durak II, Kacmaz M, Cimen MY, Buyukkock U \& Ozturk HS (2001) Blood oxidant/antioxidant status of atherosclerotic patients. International Journal of Cardiology 77, 293-297.

Francis FJ (1989) Food colorants: anthocyanins. Critical Reviews in Food Science and Nutrition 28, 273-314.

Friedewald WT, Levy RI \& Fredrikson DS (1972) Estimation of the concentration of low-density-lipoprotein cholesterol in plants without the use of preparative ultracentrifuge. Clinical Chemistry 18, 499-502.

Georgopoulos A (1999) Postprandial triglyceride metabolism in diabetes mellitus. Clinical Cardiology 22, 28S-33S.

Hennig B, Toborek M \& McClain CJ (2001) High-energy diets, fatty acids and endothelial cell function: implications for atherosclerosis. Journal of the American College of Nutrition 20 , 97S-105S.

Hertog MGL, Hollman PCH, Katan MB \& Kromhout D (1993) Intake of potentially anticarcinogenic flavonoids and their determinants in adults in the Netherlands. Nutrition and Cancer 20, 21-29.

Howarth NC, Saltzman E \& Roberts SB (2001) Dietary fibre and weight regulation. Nutrition Reviews 59, 129-139.

Kalt W, Forney CF, Martin A \& Prior RL (1999) Antioxidant 
capacity, vitamin $\mathrm{C}$, phenolics, and anthocyanins after fresh storage of small fruits. Journal of Agriculture and Food Chemistry 47, 4638-4644.

Kaplan M \& Aviram M (1999) Oxidized low density lipoprotein: Atherogenic and proinflammatory characteristics during macrophage foam cell formation. An inhibitory role for nutritional antioxidants and serum paraoxonase. Clinical Chemistry and Laboratory Medicine 37, 777-787.

Lachance PA (1998) Overview of key nutrients: macronutrient aspects. Nutrition Reviews 56, S34-S39.

Laplaud PM, Lelubre A \& Chapman MJ (1997) Antioxidant action of Vaccinium myrtillus extract on human low density lipoproteins in vitro: initial observations. Fundamentals of Clinical Pharmacology 11, 35-40.

Liu D, Manson JE, Lee I, Cole SR, Hennekens CH, Willet WC \& Buring JE (2000) Fruit and vegetable intake and risk of cardiovascular disease: the women's health study. American Journal of Clinical Nutrition 72, 922-928.

Liu Q, Scheller KK \& Schaefer DM (1996) Technical note: A simplified procedure for vitamin $\mathrm{E}$ determination in beef muscle. Journal of Animal Science 74, 2406-2410.

Loft S \& Poulsen HE (1996) Cancer risk and oxidative DNA damage in man. Journal of Molecular Medicine 74, 297-312.

Mazza B \& Oomah BO (2000) Herbs, Botanicals and Teas, pp. 289-318 [G Mazza and BO Oomah, editors]. Lancaster, Basel, USA: Technomic Publishing Co. Inc.

Middleton E, Kandaswami C \& Theoharides TC (2000) The effects of plant flavonoids on mammalian cells: Implications for inflammation, heart disease, and cancer. Pharmacological Reviews 52, 673-751.

Niki E (1996) Alpha-tocopherol. In Handbook of Antioxidants, pp. 3-25 [E Cadenas and L Parker, editors]. New York: Marcel Dekker.

Ou S, Kwok K, Li Y \& Fu L (2001) In vitro study of possible role of dietary fiber in lowering postprandial serum glucose. Journal of Agricultural and Food Chemistry 42, 1026-1029.

Papas AM (1996) Determinants of antioxidant status in humans. Lipids 31, 77S-82S.

Payne TJ (2000) Cultivated Blueberry Composition. North American Blueberry Council. http://www.blueberry.org/composit.html

Perman JA (1996) Digestion and absorption of fruit juice carbohydrates. Journal of the American College of Nutrition 15, $12 \mathrm{~S}-17 \mathrm{~S}$.

Priemé H, Loft S, Nyyssönen K, Salonen JT \& Poulsen HE (1997) No effect of supplementation with vitamin E, ascorbic acid, or coenzyme $\mathrm{Q}_{10}$ on oxidative damage estimated by 8oxo-7,8-dihydro-2'-deoxyguanosine excretion in smokers. American Journal of Clinical Nutrition 65, 503-507.

Prior RL, Cao G, Martin A, Sofic E, McEwan J, O'Brein C, Lischner N, Ehlenfeldt M, Kalt W, Krewer G \& Mainland CM (1998) Antioxidant capacity as influenced by total phenolic and anthocyanin content, maturity and variety of Vaccinium species. Journal of Agriculture and Food Chemistry 46, 2686-2693.

Rice-Evans C (2001) Flavonoid antioxidants. Current Medicinal Chemistry 8, 797-807.

Ryu JE, Howard G, Craven TE, Bond TE, Hagaman AP \& Crose JR (1992) Postprandial triglyceridemia and carotid atherosclerosis in middle aged subjects. Stroke 23, 823-828.

Salonen JT, Nyyssonen K, Salonin R, Lakka HM, Kaikkonen J, Porkkala-Saratatho E, Voutilainen S, Lakka TA, Rissanen T, Leskinen L, Tuomainen TP, Valkonen VP, Voutilainen S \& Poulsen HE (2000) Antioxidant supplementation in atherosclerosis prevention (ASAP) study: a randomized trial of the effects of vitamin $\mathrm{E}$ and $\mathrm{C}$ on 3-year progression of carotid atherosclerosis. Journal of Internal Medicine 248, 377-386.

Satué-Gracia T, Heinonen M \& Frankel E (1997) Anthocyanins as antioxidants on human low-density liposome systems. Journal of Agriculture and Food Chemistry 45, 3362-3367.

Scalbert A \& Williamson G (2000) Dietary intake and bioavailability of polyphenols. Journal of Nutrition 130, 2073S2085S.

Scheppach W, Luehrs H \& Menzel T (2001) Beneficial health effects of low-digestible carbohydrate consumption. British Journal of Nutrition 85, S23-S30.

Shi X, Schedl HP, Summers RM, Lambert GP, Chang R, Xia T \& Gisolf CV (1997) Fructose transport mechanisms in humans. Gastroenterology 113, 1171-1179.

Speek AJ, Schrijver J \& Schreurs WHP (1984) Fluorimetric detection of total vitamin $\mathrm{C}$ and total vitamin iso-C in foodstuff and beverages by high performance liquid chromatography with pre-column derivatization. Journal of Agriculture and Food Chemistry 32, 352-355.

Steinmetz KA \& Potter JD (1996) Vegetables, fruit, and cancer prevention: A review. Journal of the American Dietetic Association 96, 1027-1039.

van den Berg R, van Vliet T, Broekmans WMR, Cnubben NHP, Vaes WHJ, Roza L, Haenen GRM, Bast A \& van den Berg H (2001) A vegetable/fruit concentrate with high antioxidant capacity has no effect on biomarkers of antioxidant status in male smokers. Journal of Nutrition 131, 1714-1722.

Vendemiale G, Grattagliano I \& Altomare E (1999) An update on the role of free radicals and antioxidant defense in human disease. International Journal of Clinical and Laboratory Research 29, 49-55.

Wang H, Cao G \& Prior R (1996) Total antioxidant capacity of fruits. Journal of Agriculture and Food Chemistry 44, 701-705.

Wang SY \& Lin H (2000) Antioxidant activity in fruits and leaves of blackberry, raspberry and strawberry varies with cultivar and developmental stage. Journal of Agriculture and Food Chemistry 48, 140-146.

Willett WC (2001) Diet and cancer: One view at the start of the millennium. Cancer Epidemiology Biomarkers and Prevention 10, 3-8. 